\title{
Effect of annealing on the thermoelectric properties of directionally grown $\mathrm{Bi}_{2} \mathrm{Sr}_{2} \mathrm{Co}_{1.8} \mathrm{O}_{\mathrm{x}}$ ceramics
}

J. C. Diez ${ }^{1}$, Sh. Rasekh ${ }^{1}$, G. Constantinescu' ${ }^{1}$ M. A. Madre', M. A. Torres ${ }^{2}$, A. Sotelo ${ }^{1}$

${ }^{1}$ Instituto de Ciencia de Materiales de Aragón (CSIC-Universidad de Zaragoza), Mํㅡㄹ de Luna 3, 50018 Zaragoza, Spain.

${ }^{2}$ Departamento de Ingeniería de Diseño y Fabricación. Universidad de Zaragoza, Mª de Luna, 3. 50018 Zaragoza, Spain.

\section{Abstract}

The effect of annealing on directionally solidified $\mathrm{Bi}_{2} \mathrm{Sr}_{2} \mathrm{Co}_{1.8} \mathrm{O}_{x}$ ceramic rods has been studied for different times up to $1008 \mathrm{~h}$. Microstructure has shown five different phases in the as-grown materials which have been reduced to two major ones after $1008 \mathrm{~h}$ thermal treatment, accompanied by an important grain growth. These microstructural changes are reflected on the mechanical properties which are higher than for the as-grown materials in all cases. Moreover, they also produce an important decrease on the resistivity and increase of thermopower, leading to a raise on the power factor on thermally treated samples, about two times, compared to the as-grown samples.

Keywords: B. Platelets, C. Electrical properties, C. Mechanical properties, Thermopower 


\section{Introduction}

Thermoelectric (TE) materials with high energy conversion efficiency are strongly required for both electric power generation, in terms of waste heat recovery, and refrigeration. Thermoelectric energy conversion has been shown as an effective technology that can be used to transform thermal to electrical energy owing to the well-known Seebeck effect. This physical property allows producing electrical energy from a thermal gradient between the cold and the hot side of a thermoelectric system. The conversion efficiency of such materials is usually quantified by the dimensionless figure of merit, ZT, which is defined as $\mathrm{TS}^{2} / \rho \mathrm{\kappa}$, where $\mathrm{S}$ is the Seebeck coefficient (or thermopower), $\rho$ the electrical resistivity, $\mathrm{k}$ the thermal conductivity, and $\mathrm{T}$ is the absolute temperature [1]. As a consequence, a performant TE material involves high thermopower and low resistivity, with low thermal conductivity.

From 1997, with the discovery of large thermoelectric properties in $\mathrm{Na}_{x} \mathrm{CoO}_{2}$ [2], great efforts have been performed to explore new $\mathrm{CoO}$ families with high thermoelectric performances. Following this intense research work, some layered cobaltites, such as $\left[\mathrm{Ca}_{2} \mathrm{CoO}_{3}\right]\left[\mathrm{CoO}_{2}\right]_{1.62}$ and $\left[\mathrm{Bi}_{0.87} \mathrm{SrO}_{2}\right]_{2}\left[\mathrm{CoO}_{2}\right]_{1.82}$ were also found to exhibit promising thermoelectric properties [3-6]. Moreover, these materials can operate at high temperatures in air without degradation, as compared to the intermetallic thermoelectric compounds, which is another way for improving the ZT values.

The crystal structure of these $\mathrm{CoO}$ families is composed of two different layers, with an alternate stacking of a common conductive $\mathrm{Cdl}_{2}$-type $\mathrm{CoO}_{2}$ layer with a two-dimensional triangular lattice and a block layer, composed of insulating rock-salt-type (RS) layers. The two sublattices (RS block and $\mathrm{Cdl}_{2}$-type $\mathrm{CoO}_{2}$ 
layer) possess common $a$ - and $c$-axis lattice parameters and $\beta$ angles but different $b$-axis length, causing a misfit along the $b$-direction [7-9].

As layered cobaltites are materials with a strong crystallographical anisotropy, the alignment of plate-like grains by mechanical and/or chemical processes is necessary to attain macroscopic properties comparable to those obtained on single crystals. Some techniques have been shown to be adequate to obtain a good grain orientation in several oxide ceramic systems, as Template Grain

Growth (TTG) [9], sinter-forging [10], or directional growth from the melt [11]. In order to be adequate for practical applications, for example in power generation devices, these materials should not lose their high TE properties, as well as their mechanical ones, at high temperatures for long periods of time, usually under air.

Taking into account the results obtained in previous works [12], where several phases were obtained in the LFZ as-grown materials, the aim of the present work is studying the modification of microstructure as well as mechanical and thermoelectric properties of $\mathrm{Bi}_{2} \mathrm{Sr}_{2} \mathrm{Co}_{1.8} \mathrm{O}_{x}$ directionally grown ceramics from the melt using the laser floating zone (LFZ) technique, when they are annealed under air, for different times up to $1008 \mathrm{~h}$.

\section{Materials and methods}

The polycrystalline $\mathrm{Bi}_{2} \mathrm{Sr}_{2} \mathrm{Co}_{1.8} \mathrm{O}_{x}$ ceramics used for this study have been prepared by the classical solid state route from commercial $\mathrm{Bi}_{2} \mathrm{O}_{3}$ (Panreac, 98 $+\%), \mathrm{SrCO}_{3}\left(\right.$ Panreac, $98+\%$ ), and $\mathrm{Co}_{2} \mathrm{O}_{3}$ (Aldrich, $\left.98+\%\right)$ powders. They were weighed in the appropriate proportions, mixed and ball milled at $300 \mathrm{rpm}$ for 30 minutes, in acetone media. The resulting suspension was placed into a 
glass container and dried using an IR evaporation system. The dry powder has then been thermally treated twice at 750 and $800{ }^{\circ} \mathrm{C}$ for about 12 hours under air, with an intermediate manual milling, in order to assure the complete decomposition of the carbonates. This thermal treatment is necessary and it has been designed specifically to avoid the presence of carbonates in the following steps, as it would form $\mathrm{CO}_{2}$ bubbles in the molten zone produced in the LFZ process, producing the crystallization front destabilization. The resulting powders were then cold isostatically pressed into latex tubes at $\sim 200 \mathrm{MPa}$ for around 2 minutes to obtain green ceramic cylinders which were subsequently used as feed in a LFZ device equipped with a continuous power Nd:YAG laser $(\lambda=1.06 \mu \mathrm{m})$ and described elsewhere [13]. The processing of the different samples has been performed in the same conditions; they were directionally grown downwards from the melt at $30 \mathrm{~mm} / \mathrm{h}$ with a seed rotation of $3 \mathrm{rpm}$. Moreover, in order to assure compositional homogeneity of the molten zone, an opposite feed rotation of $15 \mathrm{rpm}$ has also been performed. Finally, after the texturing process, long (more than $15 \mathrm{~cm})$ and geometrically homogeneous $(\sim 2$ $\mathrm{mm}$ diameter) textured cylindrical rods have been produced. These bars were cut into pieces with the adequate dimensions for the thermoelectric and mechanical measurements ( $15 \mathrm{~mm}$ long) and subsequently introduced in an electric furnace at $850 \stackrel{\circ}{\mathrm{C}}$ for different time lengths (up to $1008 \mathrm{~h}$ ). The identification of the main phases in all the as-grown and annealed samples was carried out using powder XRD in a Rigaku D/max-B X-ray powder diffractometer (CuKa radiation), between 10 and 70 degrees. Microstructure evolution has been observed using a scanning electron microscope (JEOL 6000 ) equipped with an energy dispersive X-ray spectroscopy (EDS) device, 
used to determine the elemental composition of the different phases. Longitudinal polished sections of the as-grown and annealed samples have been observed to analyze the different phases, their distribution and relative alignment. Image analysis has been performed on several micrographs in order to estimate the volume fraction of each phase. Mechanical characterization has been performed by flexural strength, using the three-point bending test in an Instron 5565 machine with a $10 \mathrm{~mm}$ loading span fixture and a punch displacement speed of $30 \mu \mathrm{m} / \mathrm{min}$, as described elsewhere [14]. Electrical resistivity and thermopower were simultaneously determined by the standard dc four-probe technique in a LSR3 measurement system (Linseis $\mathrm{GmbH}$ ), in the steady state mode, at temperatures ranging from 50 to $650^{\circ} \mathrm{C}$. With the electrical resistivity and thermopower data, the power factor $\left(\mathrm{PF}=\mathrm{S}^{2} / \rho\right)$ has been calculated in order to determine the samples performances.

\section{Results and discussion}

Powder XRD patterns for the as-grown and several annealed $\mathrm{Bi}_{2} \mathrm{Sr}_{2} \mathrm{Co}_{1.8} \mathrm{O}_{x}$ textured samples (from 10 to 40 degrees, for clarity), are displayed in Fig. 1. From these data, it is clear that all the samples have very similar diffraction patterns and show a relatively low amount of secondary phases. In all the samples, the highest peaks belong to the misfit cobaltite phase and are in agreement with previously reported data $[15,16]$. Weak diffraction peaks indicated by $\bullet$ correspond to the $\mathrm{Bi}_{0.75} \mathrm{Sr}_{0.25} \mathrm{O}_{z}$ secondary phase [17] and those marked with a have been related to the $\mathrm{Sr}_{6} \mathrm{Co}_{5} \mathrm{O}_{14.3}$ phase [18]. As it can be clearly observed in Fig. 1, there is no appreciable modification of the misfit cobaltite peaks while there is a slight reduction on the secondary phases peaks 
when the annealing time is increased. This decrease on the secondary phases starts from the $72 \mathrm{~h}$ annealing time (Figure $1 \mathrm{~b}$ ) and continue until the maximum reduction is achieved at $1008 \mathrm{~h}$ (Figure 1d). This change is due to the reaction between $\mathrm{Bi}_{0.75} \mathrm{Sr}_{0.25} \mathrm{O}_{z}$ and $\mathrm{Sr}_{6} \mathrm{Co}_{5} \mathrm{O}_{14.3}$ phases, increasing the amount of the thermoelectric one.

Representative general SEM micrographs, performed on transversal polished samples, are shown in Fig. 2. In these micrographs it can be easily seen the microstructural evolution with the annealing time, from the as-grown sample (Fig. 2a) to the $408 \mathrm{~h}$ treated sample (Fig. 2b) and the $1008 \mathrm{~h}$ one (Fig. 2c). It can be easily observed a reduction on the secondary phases amount, mainly on the dark grey contrast and an increase on the thermoelectric one (grey contrast) which is in agreement with the XRD data discussed previously. In order to determine qualitatively the different phases and their amount in the samples, higher magnification micrographs have been recorded. In Fig. 3 it is represented the close view of representative as-grown and $1008 \mathrm{~h}$ thermally treated samples. In this figure it is evident the change produced in the samples microstructure with the thermal treatment. As-grown samples show five different phases, each one identified by EDS analysis and corresponding to a different contrast (numbered in Fig. 3a for clarity). When comparing as-grown samples with $1008 \mathrm{~h}$ annealed ones, it can be seen an important reduction of secondary phases: $\mathrm{CoO}$ (black contrast, \#1, 0.5 vol.\%), $\mathrm{Sr}_{2} \mathrm{Co}_{1.8} \mathrm{O}_{a}$ phase (dark grey contrast, \#2, 1.0 vol.\%), and $\mathrm{Bi}_{2} \mathrm{Sr}_{0.91} \mathrm{O}_{\mathrm{b}}$ one (white contrast, \#3, 11.0 vol.\%), to amounts lower than $0.2,0.1$, and 1.0 vol.\%, respectively, for the annealed ones. On the other hand, $\mathrm{Bi}_{2.0} \mathrm{Sr}_{1.8} \mathrm{Co}_{1.0} \mathrm{O}_{z}$ (light grey contrast, \#4, 38.0 vol.\%) slightly decrease to around 30.0 vol.\%, while the thermoelectric $\mathrm{Bi}_{2} \mathrm{Sr}_{2} \mathrm{Co}_{2} \mathrm{O}_{y}$ 
phase (grey contrast, \#5, 50.0 vol.\%) increases in an important manner to about 70.0 vol.\% after annealing process. These results indicate that the asgrown materials microstructure is a non-equilibrium one and that the annealing processes slowly allow reaching the stable equilibrium state for this composition.

In order to evaluate the mechanical behaviour evolution with the thermal treatment, flexural strength tests were made on as-grown and different timelengths thermally treated samples. At least four samples for each annealing time were used to get more representative values. The mean maximum mechanical stress, together with its relative error, is represented in Fig. 4 for the different samples. At first sight, it is clear that short thermal treatments significantly increase mechanical strength, compared with the as-grown samples. It is increasing from the as-grown samples $(0 \mathrm{~h})$ until $96 \mathrm{~h}$, with a raise of about $25 \%$ due to the reduction on the secondary phases content. Further annealing times lead to a nearly exponentially decrease, probably due to the grain sizes increase, as observed for other similar layered ceramics [19]. Moreover, these features are also reflected on the results dispersion, which is increased for high annealing times.

The effect of the annealing time on the thermoelectric properties of these ceramics has been determined by electrical resistivity and thermopower measurements. The temperature dependence of the electrical resistivity, as a function of the thermal treatment lengths, has been measured and represented in Fig. 5. As it can be easily seen, as-grown samples ( $0 \mathrm{~h}$ in Fig. 5) show a semiconducting-like behaviour $(\mathrm{d} \rho / \mathrm{dT}<0)$ in all the measured temperature range. This behaviour changes for the annealed samples to a metallic-like one 
$(d \rho / d T>0)$. The differences between both groups can be explained by the microstructural features described above. For the as-grown samples, the $\mathrm{Bi}_{2} \mathrm{Sr}_{2} \mathrm{Co}_{2} \mathrm{O}_{y}$ phase is only about 50 vol.\% (grey contrast in Fig. 3) accompanied by several secondary phases which can avoid a good electrical connectivity between adjacent $\mathrm{Bi}_{2} \mathrm{Sr}_{2} \mathrm{Co}_{2} \mathrm{O}_{y}$ phase grains. When these samples are thermally treated, not only the secondary phases content is decreased but also grain sizes and content of the thermoelectric ones are increased, leading to a reduction on the grain boundaries number and, as a consequence, to better electrical connection than for the as-grown materials. On the other hand, it is found that for longer thermal treatments than $408 \mathrm{~h}$, resistivity values are nearly unchanged due to the very large grain sizes achieved. The minimum resistivity value ( $22 \mathrm{~m} \Omega . \mathrm{cm})$ at about $300 \mathrm{~K}$ is obtained for samples thermally treated for times higher than $408 \mathrm{~h}$, and it is around the best reported values for this type of materials [20].

Fig. 6 displays the thermopower variation with temperature, as a function of the annealing time. It is evident that the sign of the thermopower is positive for the entire measured temperature range for all the samples which confirms a conduction mechanism mainly governed by holes. Following the same trends observed in the electrical resistivity measurements, the graph shows a different behaviour for as-grown and the thermally treated samples, confirming the microstructural changes effect on the thermoelectric properties. In the case of as-grown samples, it is observed a slight increase of thermopower from room temperature to around $275^{\circ} \mathrm{C}$, followed by a small decrease until about $500^{\circ} \mathrm{C}$, and remaining practically constant at higher temperatures. The thermally treated samples show a nearly linear increase on the thermopower values in the 
whole measured temperature range, with a change in the sharpness at about $275^{\circ} \mathrm{C}$, reaching a maximum value of about $220 \mu \mathrm{V} / \mathrm{K}$ at $650{ }^{\circ} \mathrm{C}$ for annealing times higher than $408 \mathrm{~h}$. In all cases, the measured thermopower values at room temperature are higher than those reported in the literature for textured materials [9].

In order to evaluate the thermoelectric performances of these materials, PF has been calculated from the resistivity and thermopower values and plotted in Fig. 7. When considering PF values at about $50 \stackrel{\circ}{ } \mathrm{C}$ ( room temperature), it can be clearly seen that as-grown samples show the lowest values (around 0.045 $\mathrm{mW} / \mathrm{K}^{2} \mathrm{~m}$ ), followed by an important increase (around 50\%) for the $192 \mathrm{~h}$ treated samples, reaching $0.065 \mathrm{~mW} / \mathrm{K}^{2} \mathrm{~m}$, which is even higher (about 100\%) for samples treated for longer times (about $0.080 \mathrm{~mW} / \mathrm{K}^{2} \mathrm{~m}$ ). The maximum measured value at $275 \stackrel{\circ}{\circ} \mathrm{C}\left(\sim 0.125 \mathrm{~mW} / \mathrm{K}^{2} \mathrm{~m}\right)$ is higher than the best obtained for single phase textured materials reported in the literature $\left(\sim 0.100 \mathrm{~mW} / \mathrm{K}^{2} \mathrm{~m}\right)$ [9].

\section{Conclusions}

This paper demonstrates the improvement of mechanical and thermoelectric properties of $\mathrm{Bi}_{2} \mathrm{Sr}_{2} \mathrm{Co}_{1.8} \mathrm{O}_{x}$ directionally grown ceramic materials when they are annealed at the adequate temperatures. The microstructural evolution has shown a reduction on the number and amount of secondary phases as well as an important grain growth with the thermal treatment. These microstructural changes are reflected on the mechanical properties which are increased until they reach a maximum after $96 \mathrm{~h}$ annealing, and decreasing nearly exponentially for higher times. In the case of the thermoelectric properties, they 
increase with time until they reach a maximum improvement after $408 \mathrm{~h}$ thermal treatment and remain practically constant for higher times. Maximum PF values at $275^{\circ} \mathrm{C}$ (about $0.125 \mathrm{~mW} / \mathrm{K}^{2} \mathrm{~m}$ ) are higher than the best reported in the literature for single phase textured materials. All these results show that $\mathrm{Bi}_{2} \mathrm{Sr}_{2} \mathrm{Co}_{1.8} \mathrm{O}_{x}$ directionally grown ceramics are promising materials for practical applications, as their TE and mechanical properties are not only decreasing but they are improved with time when they are subjected to working conditions.

\section{Acknowledgements}

The authors wish to thank the Gobierno de Aragón (Research Groups T12 and T87), the Spanish Ministry of Science and Innovation-FEDER (Project MAT2008-00429), and Universidad de Zaragoza (Project UZ2011-TEC-03) for financial support. The technical contributions of C. Estepa, J. A. Gómez and C. Gallego are also acknowledged. Sh. Rasekh acknowledges a JAE-Pre grant from CSIC. 


\section{REFERENCES}

[1] D. M. Rowe: Thermoelectrics Handbook: Macro to Nano, ed. D. M. Rowe, CRC Press, Boca Raton, Fl., 1st. edn., 2006; pp 1-3.

[2] I. Terasaki, Y. Sasago, K. Uchinokura, Large thermoelectric power in $\mathrm{NaCo}_{2} \mathrm{O}_{4}$ single crystals, Phys. Rev. B 56 (20) (1997) 12685-12687.

[3] R. Funahashi, I. Matsubara, H. Ikuta, T. Takeuchi, U. Mizutani, S. Sodeoka, An oxide single crystal with high thermoelectric performance in air, Jpn. J. Appl. Phys. 39 (11B) (2000) L1127-L1129.

[4] A. C. Masset, C. Michel, A. Maignan, M. Hervieu, O. Toulemonde, F. Studer, B. Raveau, J. Hejtmanek, Misfit-layered cobaltite with an anisotropic giant magnetoresistance: $\mathrm{Ca}_{3} \mathrm{Co}_{4} \mathrm{O}_{9}$, Phys. Rev. B 62 (1) (2000) 166-175.

[5] H. Leligny, D. Grebille, O. Perez, A. C. Masset, M. Hervieu, B. Raveau, A five-dimensional structural investigation on the misfit layer compound $\left[\mathrm{Bi}_{0.87} \mathrm{SrO}_{2}\right]_{2}\left[\mathrm{CoO}_{2}\right]_{1.82}$, Acta Cryst. B 56 (2000) 173-182.

[6] A. Maignan, D. Pelloquin, S. Hebert, Y. Klein, M. Hervieu, Thermoelectric power in misfit cobaltites ceramics: Optimization by chemical substitutions, Bol. Soc. Esp. Ceram. V. 45 (3) (2006) 122-125.

[7] A. Maignan, S. Hébert, M. Hervieu, C. Michel, D. Pelloquin, D. Khomskii, Magnetoresistance and magnetothermopower properties of $\mathrm{Bi} / \mathrm{Ca} / \mathrm{Co} / \mathrm{O}$ and $\mathrm{Bi}(\mathrm{Pb}) / \mathrm{Ca} / \mathrm{Co} / \mathrm{O}$ misfit layer cobaltites, J. Phys.-Condens. Matter 15 (17) (2003) 2711-2723.

[8] E. Guilmeau, M. Mikami, R. Funahashi, D. Chateigner, Synthesis and thermoelectric properties of $\mathrm{Bi}_{2.5} \mathrm{Ca}_{2.5} \mathrm{Co}_{2} \mathrm{O}_{x}$ layered cobaltites, J. Mater. Res. 20 (4) (2005) 1002-1008. 
[9] H. Itahara, C. Xia, J. Sugiyama, T. Tani, Fabrication of textured thermoelectric layered cobaltites with various rock salt-type layers by using $\beta$ $\mathrm{Co}(\mathrm{OH})_{2}$ platelets as reactive templates, J. Mater. Chem. 14 (1) (2004) 61-66. [10] W. Shin, N. Murayama, Thermoelectric properties of (Bi,Pb)-Sr-Co-O oxide, J. Mater. Res. 15 (2) (2000) 382-386.

[11] A. Sotelo, E. Guilmeau, M. A. Madre, S. Marinel, J. C. Diez, M. Prevel, Fabrication and properties of textured Bi-based cobaltite thermoelectric rods by zone melting, J. Eur. Ceram. Soc. 27 (13-15) (2007) 3697-3700.

[12] J. C. Diez, E. Guilmeau, M. A. Madre, S. Marinel, S. Lemmonier, A. Sotelo, Improvement of $\mathrm{Bi}_{2} \mathrm{Sr}_{2} \mathrm{Co}_{1.8} \mathrm{O}_{x}$ thermoelectric properties by laser floating zone texturing, Solid State lonics 180 (11-13) (2009) 827-830 [13] G. F. de la Fuente, J. C. Diez, L. A. Angurel, J. I. Peña, A. Sotelo, R. Navarro, Wavelength dependence in laser floating-zone processing - A casestudy with Bi-Sr-Ca-Cu-O superconductors, Adv. Mater. 7 (10) (1995) 853-856. [14] A. Sotelo, M. A. Madre, J. C. Diez, Sh. Rasekh, L. A. Angurel, E. Martinez, The influence of $\mathrm{Pb}$ and $\mathrm{Ag}$ doping on the $\mathrm{J}_{\mathrm{c}}(\mathrm{H}, \mathrm{T})$ dependence and the mechanical properties of Bi-2212 textured rods, Supercond. Sci. Technol. 22 (3) (2009) 034012.

[15] T. Itoh, I. Terasaki, Thermoelectric properties of $\mathrm{Bi}_{2.3-x} \mathrm{~Pb}_{x} \mathrm{Sr}_{2.6} \mathrm{Co}_{2} \mathrm{O}_{y}$ single crystals, Jpn. J. Appl. Phys. 39 (12A) (2000) 6658-6660.

[16] M. Kato, Y. Goto, K. Umehara, K. Hirota, K. Yoshimura, Synthesis and physical properties of Bi-Sr-Co-oxides with 2D-triangular Co layers intercalated by iodine, Physica B 378-380 (2006) 1062-1063.

[17] D. Mercurio, J. C. Champarnaud-Mesjard, B. Frit, P. Conflant, J. C. Boivin, T. Vogt, Thermal evolution of the crystal-structure of the rhombohedral 
$\mathrm{Bi}_{0.75} \mathrm{Sr}_{0.25} \mathrm{O}_{1.375}$ phase - A single-crystal neutron-diffraction study, J. Solid State Chem. 112 (1) (1994) 1-8.

[18] K. Iwasaki, H. Yamane, T. Murase, M. Yoshino, T. Ito, T. Nagasaki, Y. Arita, T. Matsui, Crystal structure of an oxygen deficient strontium cobaltate, $\mathrm{Sr}_{6} \mathrm{Co}_{5} \mathrm{O}_{14.3}$, J. Ceram. Soc. Jpn. 117 (1361) (2009) 89-93.

[19] B. Özkurt, M. A. Madre, A. Sotelo, M. E. Yakinci, B. Özçelik, Relationship between growth speed, microstructure, mechanical and electrical properties in Bi-2212/Ag textured composites, J. Supercond. Nov. Magn. DOI: 10.1007/s10948-011-1346-7. [20] J. Liu, H. S. Yang, Y. S. Chai, L. Zhu, H. Qu, C. H. Sun, H. X. Gao, X. D. Chen, K. Q. Ruan, L. Z. Cao, Study on the anomalous thermopower and resistivity of $(\mathrm{Bi}, \mathrm{Pb})-\mathrm{Sr}-\mathrm{Co}-\mathrm{O}$ : Evidence of a narrow band contribution with Anderson localization, Phys. Lett. A 356 (1) (2006) 85-88. 


\section{Figure captions}

Figure 1. XRD plots of the annealed specimens at $850^{\circ} \mathrm{C}$ for a) 0 ; b) 72 ; c) 504, and d) $1008 \mathrm{~h}$. Crystallographic planes have been indicated on the peaks corresponding to the $\mathrm{Bi}_{2} \mathrm{Sr}_{2} \mathrm{Co}_{2} \mathrm{O}_{\mathrm{y}}$ thermoelectric phase. Different symbols indicate secondary phases: $\bullet \mathrm{Bi}_{0.75} \mathrm{Sr}_{0.25} \mathrm{O}_{2}$, and $\bullet \mathrm{Sr}_{6} \mathrm{Co}_{5} \mathrm{O}_{14.3}$.

Figure 2. Representative SEM micrographs of general longitudinal polished samples thermally treated at $850^{\circ} \mathrm{C}$ during a) 0 ; b) 408 ; and c) $1008 \mathrm{~h}$.

Figure 3. Representative close view SEM micrographs of longitudinal polished samples thermally treated at $850{ }^{\circ} \mathrm{C}$ during a) 0 ; and b) $1008 \mathrm{~h}$. The different contrasts are indicated by numbers: 1. $\mathrm{CoO}$ (black contrast); 2 . $\mathrm{Sr}_{2} \mathrm{Co}_{1.8} \mathrm{O}_{\mathrm{a}}$ (dark grey contrast); 3 . $\mathrm{Bi}_{2} \mathrm{Sr}_{0.91} \mathrm{O}_{\mathrm{b}}$ (white contrast); 4. $\mathrm{Bi}_{2.0} \mathrm{Sr}_{1.8} \mathrm{Co}_{1.0} \mathrm{O}_{z}$ phase (light grey contrast); and 5. thermoelectric $\mathrm{Bi}_{2} \mathrm{Sr}_{2} \mathrm{Co}_{2} \mathrm{O}_{y}$ phase (grey contrast).

Figure 4. $\mathrm{Bi}_{2} \mathrm{Sr}_{2} \mathrm{Co}_{1.8} \mathrm{O}_{x}$ textured materials mechanical performance (three point bending), together with their standard error, as a function of the thermal treatment length.

Figure 5. Temperature dependence of the electrical resistivity of $\mathrm{Bi}_{2} \mathrm{Sr}_{2} \mathrm{Co}_{1.8} \mathrm{O}_{x}$ textured samples, as a function of time at $850^{\circ} \mathrm{C} . \bullet 0 ; 192 ; 408$; and $\wedge$ $1008 \mathrm{~h}$. 
Figure 6. Temperature dependence of the thermopower, of $\mathrm{Bi}_{2} \mathrm{Sr}_{2} \mathrm{Co}_{1.8} \mathrm{O}_{x}$ textured samples, as a function of time at $850^{\circ} \mathrm{C}$. $\bullet 0$; 192; 408; and $\boldsymbol{\Delta}$ $1008 \mathrm{~h}$.

Figure 7. Temperature dependence of the power factor, of $\mathrm{Bi}_{2} \mathrm{Sr}_{2} \mathrm{Co}_{1.8} \mathrm{O}_{x}$ textured samples, as a function of time at $850^{\circ} \mathrm{C}$. $\bullet 0$; 192; 408; and $\triangle$ $1008 \mathrm{~h}$. 
Figure 1

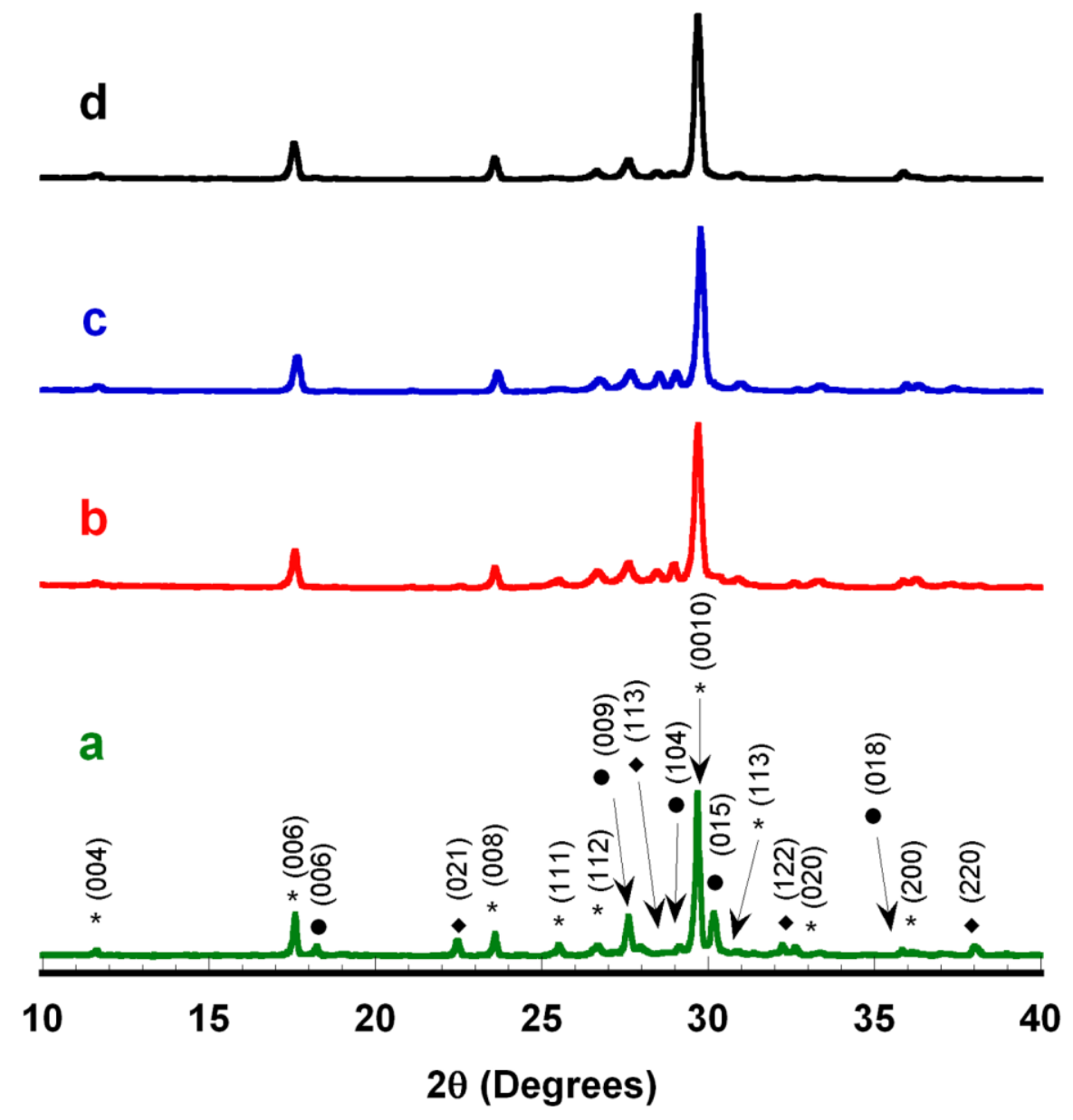


Figure 2
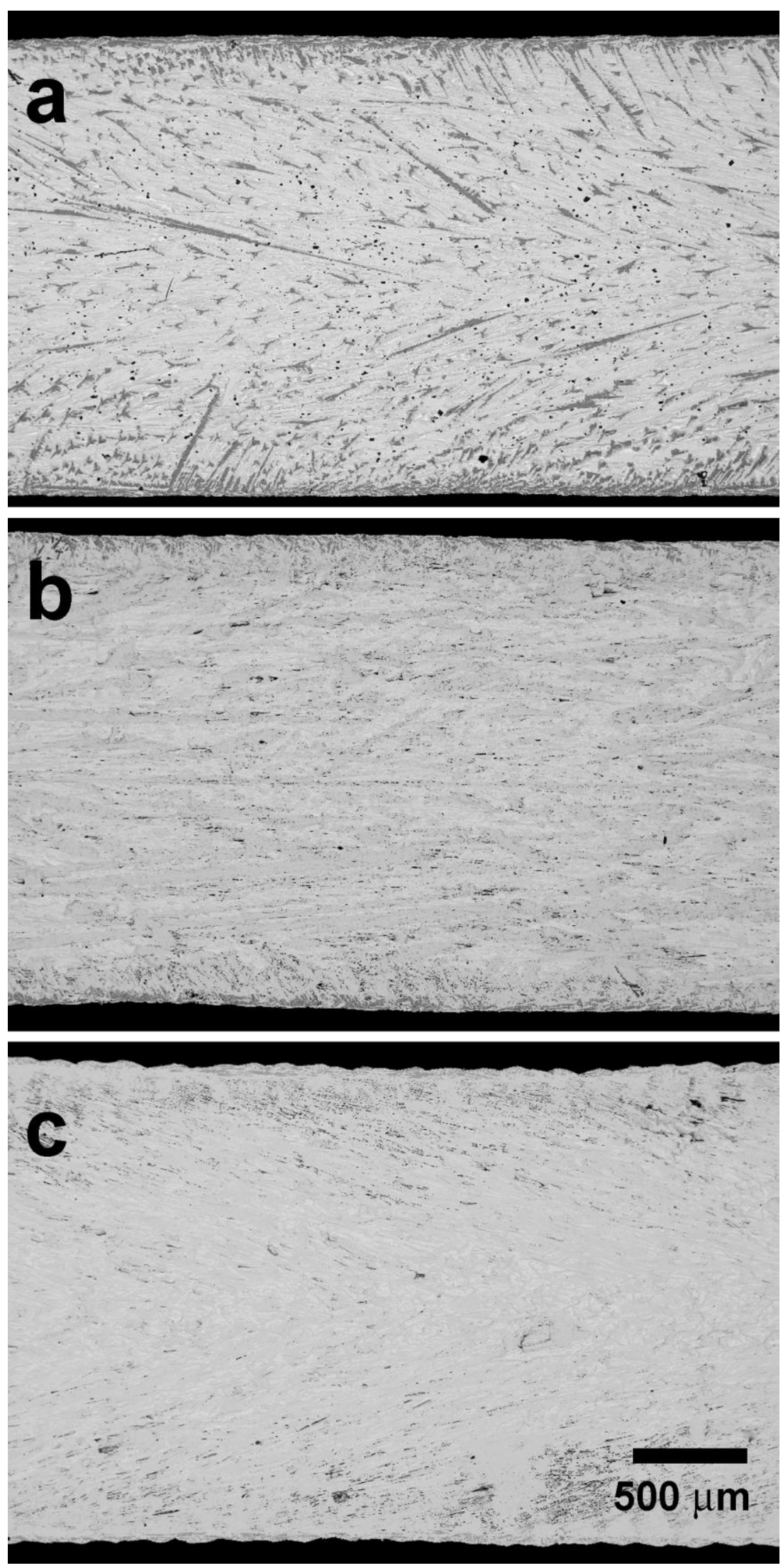
Figure 3
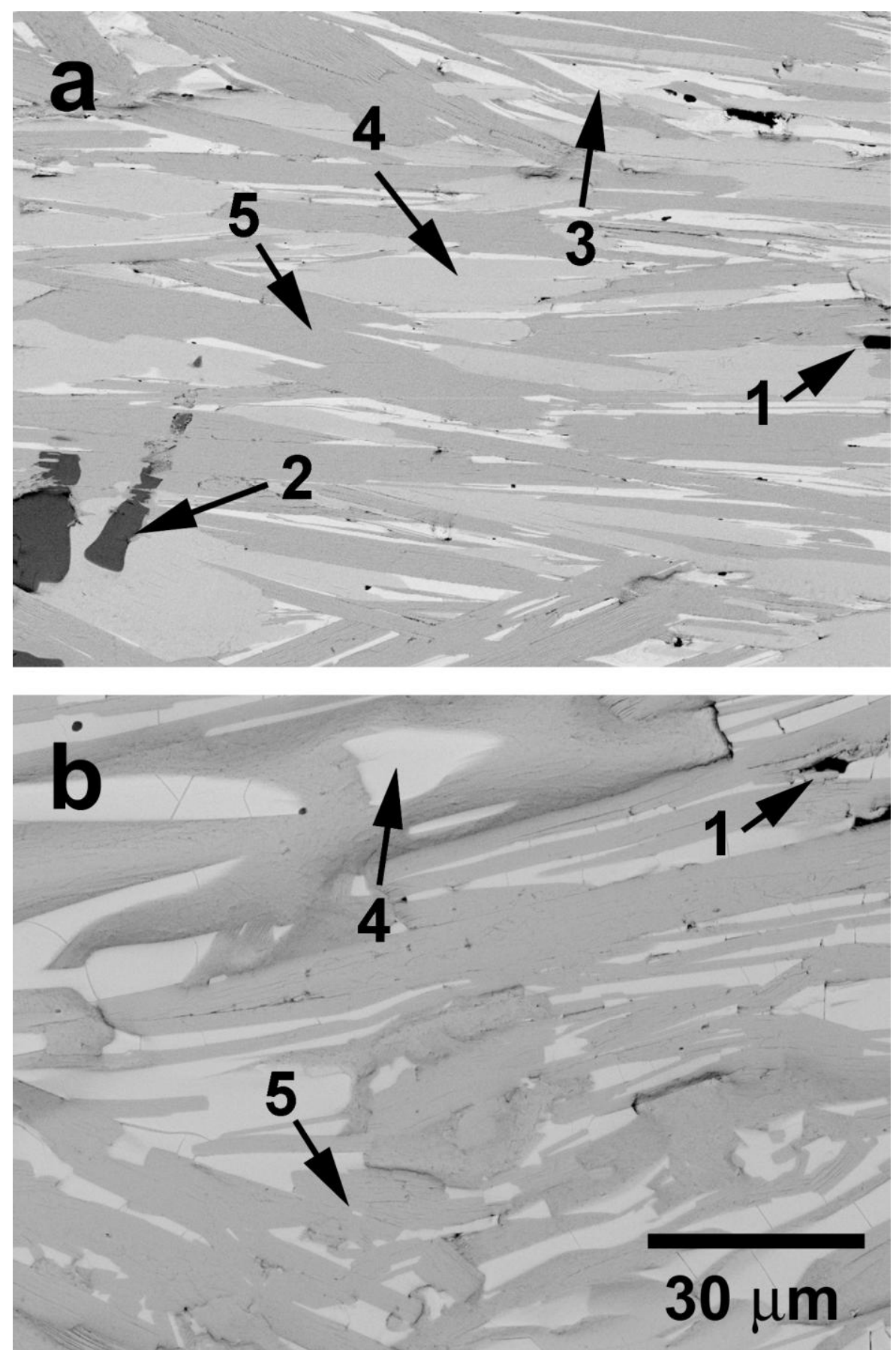
Figure 4

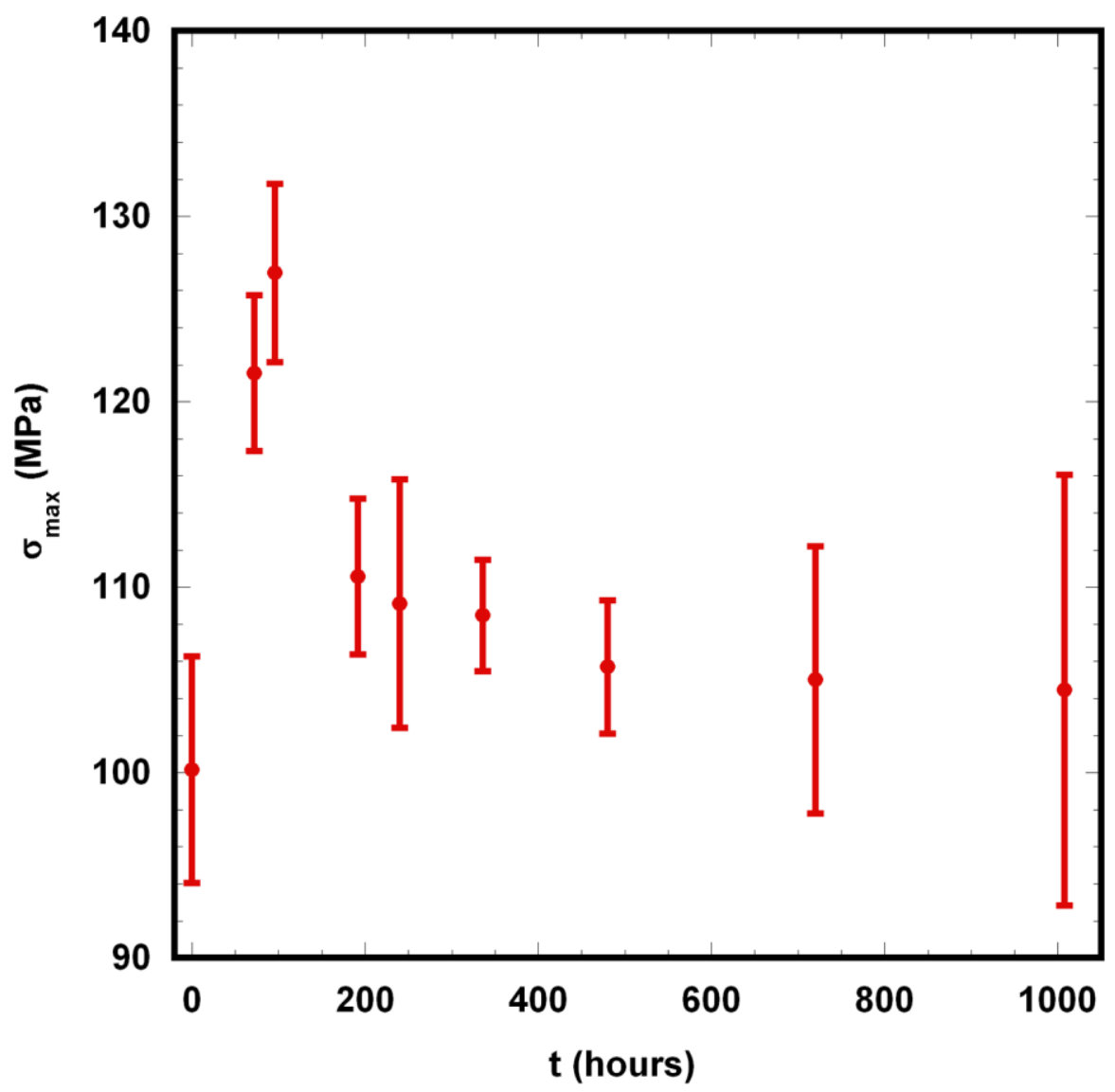


Figure 5

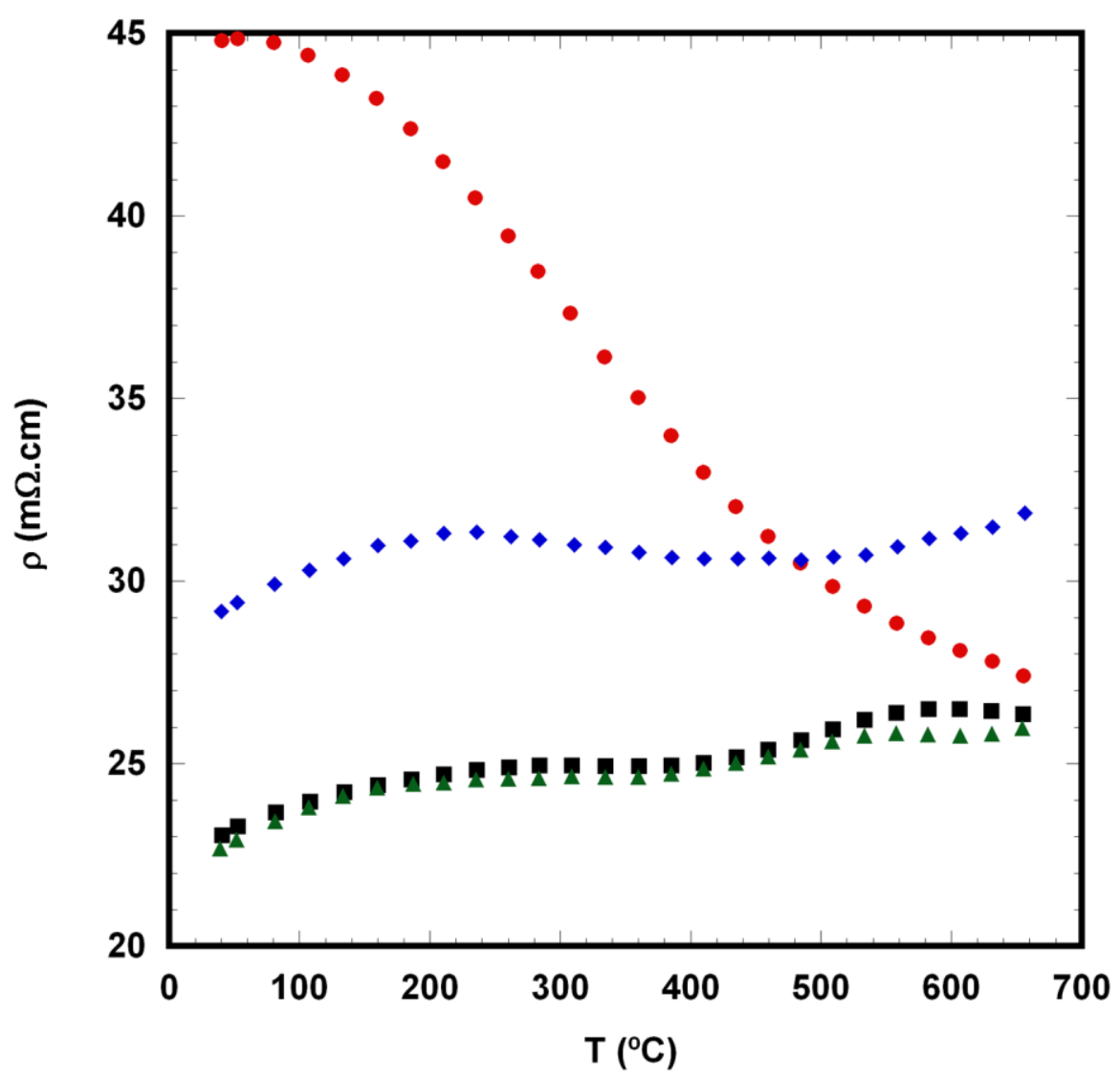


Figure 6

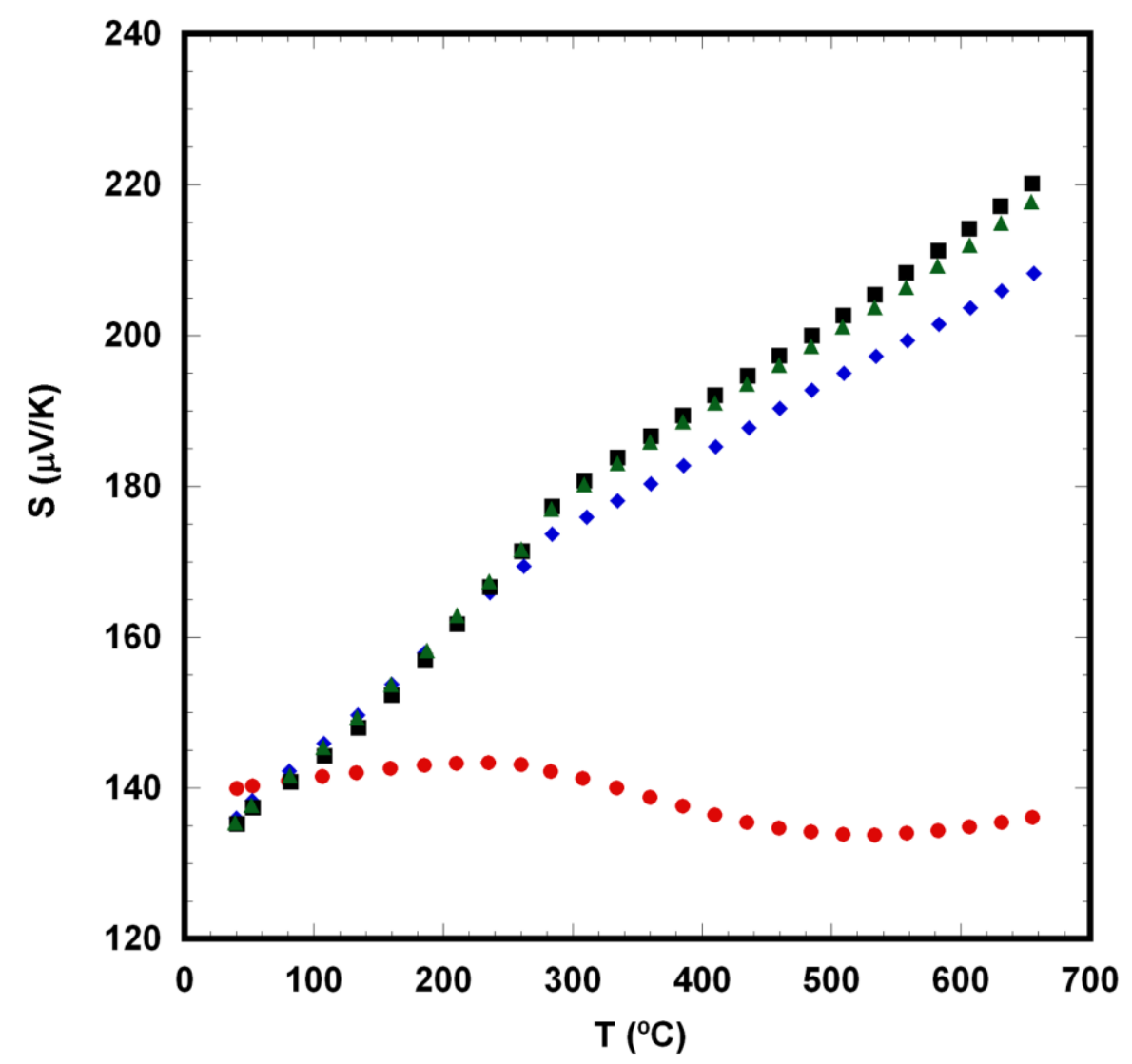


Figure 7

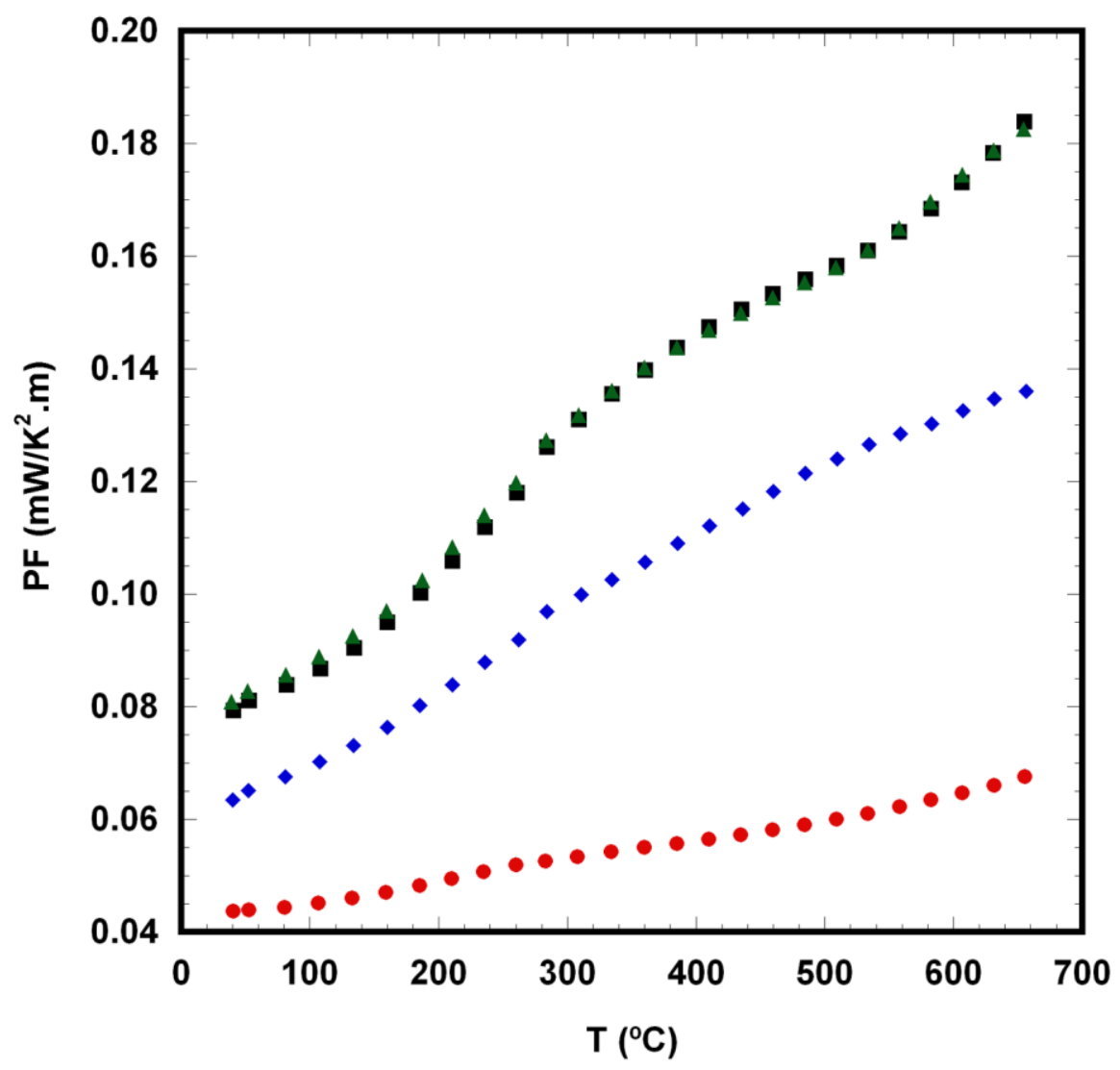

